\title{
INTERDISCIPLINARIDADE NA FONOAUDIOLOGIA: A CONCEPÇÃO DO PROFESSOR
}

\section{Interdisciplinarity in speech language therapy: the teacher's conception}

\author{
Renata Mancopes ${ }^{(1)}$, Luiz Roberto Agea Cutolo ${ }^{(2)}$, Danielle Tesch ${ }^{(3)}$, Fernanda Schultz ${ }^{(4)}$, \\ Rafaela Bittencourt Pedroso Santos ${ }^{(5)}$, Rafaela Mafatti (6), Taisa da Silva ${ }^{(7)}$
}

\begin{abstract}
RESUMO
Objetivo: analisar a concepção de interdisciplinaridade referida pelos professores fonoaudiólogos do curso de Fonoaudiologia da Universidade do Vale do Itajaí. Métodos: a pesquisa orientou-se por uma abordagem qualitativa através da Análise do Discurso de Linha Francesa, tendo como instrumento de coleta de dados a entrevista em profundidade. Resultados: após a análise, identificaram-se diferentes posições sujeito, onde se podem observar a concepção e o conhecimento sobre a interdisciplinaridade, as possíveis situações pedagógicas nas quais a interdisciplinaridade acontece, além dos obstáculos às práticas interdisciplinares. Conclusão: percebeu-se que não há ainda um conhecimento sedimentado sobre a interdisciplinaridade que resulte numa linha de trabalho com princípios teórico-metodológicos suficientemente definidos e consistentes. Por fim, este trabalho revela a necessidade de maior investimento em pesquisas a fim de sustentar os princípios da interdisciplinaridade no campo da Fonoaudiologia, com intuito de expandir os horizontes desse profissional que, antes de tudo, precisa entender-se como profissional da saúde o qual vive cotidianamente uma realidade que exige um olhar plural.
\end{abstract}

DESCRITORES: Equipe de Assistência ao Paciente; Educação Profissionalizante; Comunicação Interdisciplinar

\section{INTRODUÇÃO}

O fonoaudiólogo como profissional da saúde, precisa entender todos os aspectos que abrangem a interdisciplinaridade para atuar segundo as novas diretrizes curriculares preconizadas pelo Ministério da Saúde e o Ministério da Educação ${ }^{1}$. A complexidade do objeto saúde/doença não possibilita uma

(1) Fonoaudióloga; Docente do Curso de Fonoaudiologia da Fundação Universidade Federal de Ciências da Saúde de Porto Alegre, UFCSPA, Porto Alegre, RS; Mestre em Letras; Doutora em Linguística pela Universidade Federal de Santa Catarina.

(2) Médico Pediatra; Professor do Programa de Mestrado em Saúde e Gestão do Trabalho da Universidade do Vale do Itajaí, UNIVALI, Itajaí, SC; Mestre e Doutor em Educação pela Universidade Federal de Santa Catarina.

(3) Aluna do Curso de Graduação em Fonoaudiologia.

(4) Aluna do Curso de Graduação em Fonoaudiologia.

(5) Aluna do Curso de Graduação em Fonoaudiologia.

(6) Aluna do Curso de Graduação em Fonoaudiologia.

(7) Aluna do Curso de Graduação em Fonoaudiologia.

Conflito de interesse: inexistente visão de exclusividade disciplinar. Somente categorias interdisciplinares de investigação, com produções coletivas, podem promover aproximações do entendimento quanto a essa complexidade ${ }^{2}$.

A malha complexa de interações que permitem o entendimento da saúde/doença exige um olhar plural ${ }^{2,3}$. Extrapolando o que autor ${ }^{4}$ referenciou sobre a medicina, poder-se-ia dizer que em ciências da saúde não existe a possibilidade de uma consideração unitária, há a necessidade de observações distintas dos fenômenos.

A existência da consideração plural exige o exercício de práticas pedagógicas rotineiras menos pretensiosas e restritivas que impedem abertura para novos olhares ${ }^{1}$.

A interdisciplinaridade, na área da saúde, é um tema pouco investigado. Partindo-se do pressuposto de que a dificuldade da interdisciplinaridade pode estar relacionada com a formação recebida durante a graduação, o perfil do profissional começa a ser elaborado e determinado pelas práticas curriculares, principalmente pelo discurso do corpo docente, 
importante no processo de formação do futuro profissional $^{2}$.

Autor ${ }^{5}$ enfatiza que ao colocar os alunos diante dos enfrentamentos dos problemas de saúde, deve-se, em primeira instância, admitir que esses problemas são necessariamente interdisciplinares, e que as realidades que os permeiam são realidades interdisciplinares.

O movimento da interdisciplinaridade surgiu em resposta ao modelo positivista vigente até então na teoria do conhecimento. A imposição e a predominância harmônica da metodologia positivista levaram os cientistas a uma fragmentação do saber, sendo que somente ao final da década de 50 , a necessidade de uma proposta interdisciplinar é colocada mais claramente em discussão ${ }^{6}$.

A busca pela interdisciplinaridade não significa a defesa de um saber genético, enciclopédico, eclético ou sincrético. Não se trata de substituir as especificidades por generalidades, nem o seu saber por um saber geral, sem especificações e delimitações ${ }^{3}$.

A interdisciplinaridade aparece para promover a superação da superespecialização e da desarticulação entre teoria e prática como alternativa à disciplinaridade ${ }^{7}$. O trabalho interdisciplinar se caracteriza pela intensidade das trocas entre os especialistas e pelo grau de integração real das disciplinas no interior de um mesmo projeto de pesquisa ${ }^{8}$.

A interdisciplinaridade deve ser entendida como a possibilidade do trabalho conjunto na busca de soluções, respeitando-se as bases disciplinares específicas, além de estabelecer relação articulada entre as diferentes profissões da saúde ${ }^{9}$.

Também é uma questão de atitude. É uma relação de reciprocidade que pressupõe uma conduta diferenciada diante do problema do conhecimento, ou seja, é a substituição de uma concepção fragmentária para uma concepção unitária do ser humano ${ }^{10}$.

Está também associada ao desenvolvimento de habilidades, tais como: flexibilidade, confiança, paciência, intuição, capacidade de adaptação, sensibilidade em relação às demais pessoas, aceitação de riscos, ação na diversidade, aceitação de novos papéis.

A interdisciplinaridade é fundamentalmente um processo e uma filosofia de trabalho que entram em ação na hora de enfrentar os problemas e questões que preocupam cada sociedade ${ }^{8}$.

O objetivo deste trabalho é analisar a concepção de interdisciplinaridade referida pelos professores fonoaudiólogos de um curso de Fonoaudiologia, a fim de contribuir para o debate da formação do fonoaudiólogo, na perspectiva de que sua ação se constitua na lógica de construção do conhecimento e de práticas plurais que atendam à nova demanda da complexidade do objeto saúde/doença.

\section{MÉTODOS}

A pesquisa enfocou o conhecimento sobre a interdisciplinaridade referido por sete professores fonoaudiólogos, procurando conhecer sua concepção sobre o tema pesquisado, as situações pedagógicas (possíveis ou não para tal prática) e os obstáculos para sua atuação. Todos os professores que aceitaram participar da pesquisa possuíam, no momento da pesquisa, o título de mestre e ministravam diferentes disciplinas no curso de Fonoaudiologia, as quais se incluíam: estágios supervisionados, disciplinas teóricas, entre elas, a de Estudo de Caso em Fonoaudiologia e Tópicos Essenciais em Fonoaudiologia, sendo, alguns dos professores, também responsáveis por projetos de extensão. Procuraram-se, ainda, elencar disciplinas de todos os períodos do curso (do primeiro ao oitavo período).

Os critérios para seleção e inclusão dos sujeitos na pesquisa seguiram os princípios da amostra intencional. Esta amostragem é selecionada com base no julgamento das necessidades dos pesquisadores de que determinados elementos (um ou mais critérios) sejam os mais representativos da população e permite aumentar a utilização dos dados obtidos a partir de pequenas amostras ${ }^{11}$. Portanto, os professores foram selecionados a partir da experiência e vivência cotidiana dos pesquisadores no curso de Fonoaudiologia, os quais elegeram informantes considerados potenciais para os objetivos da pesquisa. Dentre os critérios utilizados para a seleção, consideraram-se as disciplinas e atividades propostas na matriz curricular que se predispunham à questão da interdisciplinaridade, assim como os profissionais ligados ao estágio e à gestão do curso, por entendê-los como protagonistas na formação profissional do fonoaudiólogo.

A abordagem da pesquisa foi qualitativa, cuja principal característica baseia-se na compreensão e integração de um comportamento ou evento, assim como nas inter-relações que emergem de um dado contexto ${ }^{11}$, bem como na busca da compreensão particular do objeto de pesquisa ${ }^{12}$.

A entrevista em profundidade foi escolhida para a coleta de dados, já que propicia interação constante entre o pesquisador e o sujeito da pesquisa ${ }^{13}$, possibilitando uma coleta de dados mais completa.

A partir de um roteiro preliminar, foram aplicadas quatro questões abertas, semi-estruturadas, permitindo às entrevistadoras e aos entrevistados realizar adaptações no decorrer da entrevista. As questões solicitavam do entrevistado o relato da história de 
sua formação até o momento da entrevista e quais suas ideias e concepções a respeito de interdisciplinaridade. Além disso, solicitava-se também que o entrevistado apontasse quais as situações pedagógicas em que considerava as práticas interdisciplinares aplicáveis e, ainda, se havia espaços no curso de Fonoaudiologia em que acreditava ser possível executar práticas interdisciplinares e o porquê.

As entrevistas tiveram a duração média de 60 minutos. $O$ registro foi feito em fita cassete, com posterior transcrição dos dados. A análise foi realizada em aproximação à Análise do Discurso de Linha Francesa, tal qual delineada por Michel Pêcheux ${ }^{14}$.

A análise do material transcrito foi realizada durante seis meses, conforme previsto pelo cronograma da pesquisa, e deu-se após leitura exaustiva e flutuante dos dados. Discutiu-se a transcrição dos relatos e selecionaram-se os fatos discursivos importantes de acordo com os objetivos da pesquisa e da emergência de sentidos repetíveis e significativos no discurso dos entrevistados. Após essa primeira etapa de análise, foi realizado recorte dos fatos considerados importantes, reunindo-os em blocos e grupos discursivos, conforme as categorias de análise elencadas durante a etapa de recorte. A análise se organiza, portanto, em blocos discursivos (BD), que contêm grupos discursivos (GD), os quais, por sua vez, se constituem de sequências discursivas ( $\mathrm{Sd}$ ).

A investigação foi norteada por três eixos discursivos que remetiam aos objetivos de pesquisa, a saber: o conceito sobre interdisciplinaridade, as situações pedagógicas possíveis e os obstáculos às práticas interdisciplinares.

Para a Análise do Discurso, os discursos representam, por sua significação e repetição, o processo de produção de sentido. Logo, os fatos discursivos selecionados caracterizaram os sentidos principais atribuídos à interdisciplinaridade no contexto das práticas pedagógicas do curso, assim como os obstáculos a essas práticas ${ }^{15}$.

O presente trabalho fez parte do projeto de pesquisa "Práticas Curriculares Interdisciplinares dos Cursos de Graduação em Saúde da UNIVALI (Campus I)", aprovado pelo Comitê de Ética, sob o número 377/2003 e foi realizado nas dependências do Curso de Fonoaudiologia.

\section{RESULTADOS}

O Bloco discursivo 1 corresponde à análise da designação da interdisciplinaridade; o Bloco discursivo 2, à das situações pedagógicas; e no Bloco discursivo 3 analisaram-se os obstáculos encontrados para realizar a prática interdisciplinar.
No Bloco Discursivo 1 foram identificados dois funcionamentos discursivos distintos (GD1 e GD2), nos quais se pode observar o conhecimento indeterminado sobre a interdisciplinaridade e um conhecimento preliminar. As sequências a seguir são exemplares dos dados coletados:

Grupo 1. Sd1 "Pra mim, assim eu entendo que é quando você tem um paciente, que todos os profissionais que estão envolvidos crêem, juntamente com este paciente, que consiga discutir com cada um deles o que está acontecendo, se está evoluindo ou não, quais as interferências que este paciente tem, quais são as limitações deste paciente, e de que forma que a fisioterapeuta ou a psicóloga pode até me auxiliar, e eu de contrapartida com eles também, pra que a gente possa ter uma boa condução desse caso. Então, isso pra mim é a realidade mais correta que possa existir".

Grupo 2. Sd3 "Eu posso dizer que a interdisciplinaridade é uma inter-relação entre disciplinas, que é muito diferente de você dizer uma soma teórica de disciplinas, né? Multi é quantidade que estariam alocadas trabalhando junto, interdisciplinaridade, o conceito vai perpassar pela idéia de inter-relação, que, quando se articula uma coisa com a outra, o resultado disso não é nem a primeira, não a somatória de uma parte com a outra parte, mas é a interrelação na medida que você relaciona uma coisa com outra, você já está transformando tanto uma como a outra".

O Bloco Discursivo 2 apresenta a análise das situações pedagógicas referidas pelos fonoaudiólogos como aquelas possíveis para a interdisciplinaridade, o que se pode observar nos exemplares a seguir, subdivididos em três grupos discursivos, a saber:

Grupo 1. Sd1 “Há talvez os projetos de extensão, acho que é uma coisa que tá funcionando bastante, né, porque os projetos e extensão geralmente são vários profissionais (...) então, quando você tem um projeto de extensão, você tem um horário pra aquilo, e é toda uma equipe que tá trabalhando bem integrada, né? O que eu vejo, assim, que eu assisto até da apresentação destes projetos que funcionam bastante".

Grupo 2. Sd 1 "Não é que nunca teve, tivemos agora em julho, essa já tivemos algumas tentativas, posso te dizer que temos pontos isolados, ações isoladas de interdisciplinaridade".

Grupo 3. Sd 3 "A saúde pública acaba resgatando muito as disciplinas de saúde pública, de saúde coletiva, tem que resgatar vários conteúdos e acaba lembrando um pouquinho dessas atividades interdisciplinares. Mas eu não vejo dificuldades, não, em nenhum local, nenhum setor, nenhuma disciplina aqui. Acho que é isso". 
No Bloco Discursivo 3, reúne-se a análise dos obstáculos identificados no discurso dos professores quanto à interdisciplinaridade em quatro grupos discursivos apresentados a seguir:

Grupo 1. Sd 2 "Acho que existem muitas coisas que impedem, primeiro questão teórica de se entender o que é interdisciplinaridade, às vezes a gente vê muito no discurso do profissional da saúde o multi como sendo inter, né, e não é, a falta de integração entre os profissionais da saúde, cada um fica isolado na sua, no seu prédio".

Grupo 2. Sd 2 "Aí, seria uma reflexão, assim, eu não sei te dizer o quê. Não sei se talvez a falta de tempo, que nós professores temos em todos os cursos, e talvez a própria falta de cultura, mesmo, de ter este tipo de trabalho".

Grupo 3. Sd 1 "Então, assim, por exemplo, agora todo mundo se forma e quer fazer especialização, então, eu vou saber muito de voz, eu vou saber muito de áudio, eu vou saber muito de linguagem, então, muitas vezes essa postura da profissão leva, às vezes, a uma dificuldade dentro do próprio curso, dele ser, dele executar, então, assim, quantas vezes a áudio tá fazendo uma coisa que seria super importante pra saúde pública, e às vezes os dois setores não se conversam, né, porque estão construindo conhecimentos diferentes, né? Então, eu acho que tem o contexto da profissão, tá repercutindo aqui, e que não está favorecendo uma maior construção dessas práticas, mesmo".

Grupo 4. Sd 1 "É viável, hoje em dia, para poucos, porque, pra você montar uma clínica, você tem que ter afinidades com esta equipe, você pode até ter o profissional ali com você (...)".

\section{DISCUSSÃO}

No Bloco Discursivo 1, os funcionamentos discursivos explicitados em GD1 e GD2 definem duas posições sujeito no discurso que apontam para a heterogeneidade e a possibilidade de divisão e diferença dentro de um mesmo discurso ${ }^{14}$. Desse modo, no discurso sobre a interdisciplinaridade, há divisão e diferença de concepções, o que denota um conhecimento ainda não consolidado em relação ao tema. Porém, ao identificar duas posições sujeito possíveis no discurso dos fonoaudiólogos, acredita-se que não há estagnação de saberes, e sim, movimento de construção do saber sobre a interdisciplinaridade.

$\mathrm{Na}$ Sd1 observa-se um funcionamento discursivo que se movimenta da generalização marcada por "todo" à especificação marcada por "cada um". A sequência mostra a determinação na língua e o jogo entre a indeterminação no discurso, que acaba por não definir o sentido da interdisciplinaridade. A concepção explicitada nessa sequência aponta também para uma assimetria de lugares das áreas mencionadas, marcada pela expressão "pode até". Assim, nesse segmento discursivo, o efeito de sentido que relaciona a psicologia e a fisioterapia à fonoaudiologia é o de subordinação.

Tal fato vai de encontro à relação interdisciplinar, já que, mesmo havendo aproximações que podem implicar confrontos, é necessário que as disciplinas colaborem entre si de maneira conjunta e horizontalizada, tendo como base a autêntica vontade de colaboração, cooperação, diálogo e abertura para o outro, respeitando seus limites ${ }^{16}$.

$\mathrm{Na}$ Sd3 observa-se inicialmente um fato discursivo que referenda as discussões apresentadas na literatura da área quanto à dificuldade em conceituar a interdisciplinaridade. Observa-se que, na tentativa de definição, o discurso torna-se confuso, expressando certa inconsistência do conhecimento sobre interdisciplinaridade por falta de suporte teórico. Tal fato é referido em "de acordo com que tenho lido" e "o que a gente vê na literatura", mas não é nomeado. É necessário evitar as confusões sistemáticas atribuídas à interdisciplinaridade e fazse necessário distingui-la em relação aos termos multidisciplinaridade e transdisciplinaridade.

A multidisciplinaridade refere-se a articulação entre as disciplinas. Já a transdisciplinaridade, diz respeito à conjugação dos saberes disciplinares para um mesmo objetivo, transpondo as particularidades. Ela comporta a inter e a multidisciplinaridade, passando do simples ao complexo ${ }^{17}$.

O sentido do termo interdisciplinaridade não é estável, visto que se trata de uma palavra que não é sempre compreendida da mesma forma ${ }^{18}$.

Ainda na Sd3, a ideia de construção e inter-relação aponta não apenas para o sentido do trabalho cooperativo, mas também para o grau de colaboração e tangenciamento das disciplinas. A construção de um outro conhecimento como produto da relação entre as disciplinas, resulta em construção conjunta de teorias, conceitos e abordagens ${ }^{9}$. Ressalta-se que, na Sd3, observou-se que as expressões "inter-relação" e "articula" apontam para uma relação estreita entre as disciplinas, cujo resultado é negado como um mero somatório de partes e remete para à afetação mútua entre as disciplinas, evidenciada pela expressão "transformando tanto uma como a outra".

Destaca-se a necessidade de abertura das especificidades no processo de interação entre os conhecimentos, já que somente ao exteriorizar o que se sabe e interiorizar o que se recebe numa relação interdisciplinar é que se consegue uma visão de totalidade de uma dada situação ${ }^{18}$. Desse 
modo, vê-se que a relação interdisciplinar pressupõe a afetação mútua entre as disciplinas ${ }^{19}$.

Analiticamente, pode-se afirmar que a indeterminação de sentidos produzida nesse bloco discursivo emerge do interdiscurso. O interdiscurso é o conjunto do dizível, histórica e linguisticamente definido ${ }^{20}$. Essa indeterminação, portanto, reflete o conjunto de formulações já ditas ao longo da história da noção de interdisciplinaridade que se apresenta no discurso dos fonoaudiólogos.

A partir da análise do Bloco Discursivo 1, destaca-se que, apesar de ainda inconsistente, o conhecimento sobre interdisciplinaridade está colocado como possibilidade de ações na prática de fonoaudiólogo. Acredita-se, também, ser possível um pensar/fazer interdisciplinar na Fonoaudiologia, na medida em que se identifica certo conhecimento preliminar à área.

A análise do Bloco Discursivo 2 reforça os aspectos analisados no Bloco Discursivo 1, demonstrando por um lado, situações definidas a partir de um conhecimento preliminar sobre a interdisciplinaridade e, por outro, situações inespecíficas ou intra-disciplinares, que podem resultar de um conhecimento indeterminado sobre o tema. Ressalta-se que a relevância desse bloco discursivo centra-se na identificação rudimentar de alguns espaços potenciais para as práticas disciplinares no curso de Fonoaudiologia. Esses espaços podem ser compreendidos como objetos fronteiriços, já que se podem identificar práticas ou área de domínio comum que sofrem cooperação de mais coletivos de pensamento para sua compreensão ${ }^{21}$.

A particularidade da Sd1 do GD1 é apontar para uma situação pedagógica que transcende os limites do curso e que ocorre no espaço mais amplo da universidade, relacionando com o meio social: os projetos de extensão.

Nas situações pedagógicas específicas do curso, foram identificadas a disciplina de tópicos essenciais, o estudo de caso no estágio do sétimo período do curso e o estágio de saúde pública. As situações pedagógicas elencadas nesse grupo discursivo confirmam a diversidade constante na Fonoaudiologia, discutida no segundo capítulo deste trabalho. Tanto em nível de disciplinas, estágios de diferentes áreas, como em projetos de extensão, observam-se pontos de contato com outras áreas os quais permitem a interdisciplinaridade.

Dentro do curso de Fonoaudiologia, a disciplina de Tópicos Essenciais possibilita um despertar para os objetos fronteiriços, pois favorece uma comunicação entre diversos profissionais de outras áreas e os acadêmicos, gerando diálogo, troca de informações e de ideias. Tal situação pedagógica possibilita o exercício da escuta em relação ao que o outro profissional tem a dizer e o reconhecimento das zonas de contato entre áreas afins o que ultrapassa a divisão disciplinar clássica do conhecimento científico ${ }^{2}$.

Outra possibilidade dentro do curso parece ser - Estágio de Saúde Pública, pela abrangência e complexidade da área, que exige um olhar plural de todos os profissionais da saúde envolvidos no sistema. Na Saúde Pública, a interdisciplinaridade se coloca como uma exigência interna, uma vez que o objeto de trabalho saúde-doença, em seu âmbito social, envolve relações comunitárias, expressões emocionais e repercussões biológicas. Isso quer dizer que Saúde Pública, diferente da área clínica, que tende a uma visão biologicista, contempla a interdisciplinaridade mais do que outras áreas. A área clínica parece estar mais ligada à questão da especificidade. Na Saúde Pública, os limites de cada área parecem se cruzar.

Nota-se que, dentro das situações pedagógicas (disciplinas, estágios, projetos de extensão, etc.), identificam-se objetos fronteiriços potenciais relacionados a situações concretas no trabalho em saúde. Objetos fronteiriços poderiam ser entendidos como conceitos, técnicas, materiais de domínio de uma área (ou de um coletivo de pensamento), que possuem compatibilidade com outros coletivos. O objeto fronteiriço viabiliza a interdisciplinaridade através da possibilidade dialógica diminuindo a contradição entre os discursos ${ }^{21}$.

Além disso, ao levantar as situações pedagógicas, identifica-se a presença de iniciativas, no sentido de promover a interdisciplinaridade, que podem apontar para certa disponibilidade desse curso em construir práticas interdisciplinares.

A análise do Bloco Discursivo 3 permite ver o que o próprio docente do curso de Fonoaudiologia apontou como aspectos que devem ser refletidos na busca de um trabalho interdisciplinar, visto que a interdisciplinaridade não pode ser conteúdo ou objeto de apenas uma aula. Entende-se que o currículo precisa criar condições para que a interdisciplinaridade desenvolva-se como uma temática transversal, que deve permear um grupo todo de saberes e práticas. A interdisciplinaridade passa a ser transversal à medida que, durante o curso, haja interação com outros profissionais da saúde que fazem parte do cotidiano dos alunos.

Na Sd2 do GD1, observou-se que a relação entre teoria e prática coloca-se como obstáculo à interdisciplinaridade, na medida em que a prática parece ser insipiente, porque não há domínio teórico suficiente, há indistinção entre conceitos correlatos como multidisciplinaridade e, também, porque não há integração entre os profissionais de saúde que pode limitar a aplicação da teoria. Já, na Sd2 
do GD2, o tempo é apontado como obstáculo à efetivação de práticas interdisciplinares, o que estabelece também uma falta de cultura em relação a essas práticas.

Destaca-se que, no GD3, a Sd1 é representativa quanto aos obstáculos referidos ao contexto de formação profissional, no qual há o privilégio da especialização em detrimento da formação geral, que poderia viabilizar a interdisciplinaridade. Destaca-se que esse contexto não parece ser privilégio da Fonoaudiologia, à medida que o movimento dos órgãos responsáveis pela Saúde e Educação no país é de uma nova construção de saberes para a formação dos profissionais da Saúde em geral. Além disso, no GD4, a Sd1 é representativa da questão da atitude do profissional como operadora de relações interdisciplinares. À medida que as "afinidades" da equipe parecem ser uma necessidade, percebe-se que a atitude dos profissionais pode marcar diferença na construção de práticas interdisciplinares, na busca de uma linguagem comum e certa disponibilidade interna para fazê-lo.

Os obstáculos elencados nesse bloco discursivo perpassam uns aos outros, visto que há atravessamentos entre eles, como a relação teórico-prática, que também faz parte na questão de formação. Assim como a falta de tempo pode afetar a viabilidade de uma cultura mais voltada à interdisciplinaridade, em detrimento da especialização tão presente no contexto de formação, a interdisciplinaridade é uma relação de afetação mútua e de reciprocidade que indica a necessidade de uma compreensão unitária do ser humano ${ }^{10,16}$.

O positivismo é considerado um dos maiores obstáculos à interdisciplinaridade e à construção da integralidade, sendo um dos principais responsáveis pela fragmentação do saber ${ }^{6,22}$.

Outro obstáculo levantado é a configuração da divisão sócio-técnica do trabalho e da constituição dos saberes. Percebe-se que cada profissão se insere no mercado de trabalho de forma gradativa, buscando conquistar seu espaço, havendo, muitas vezes, competições entre diferentes áreas ${ }^{18}$. A própria conceituação de interdisciplinaridade, confundida, muitas vezes, com outros termos como disciplinaridade, multidisciplinaridade, pluridisciplinaridade e transdisciplinaridade, se coloca como obstáculo à interdisciplinaridade ${ }^{18}$, mesmo quando nenhum desses termos se bastam e sim apresentam uma contribuição a dar, sendo o mais importante a atitude epistemológica ${ }^{17}$.

Também é necessária a colaboração entre os profissionais, respeitando-se os limites de cada área, pois as disciplinas que preservam suas particularidades e especificidades de modo radical dificultam uma verdadeira relação interdisciplinar ${ }^{14}$.
Assim, um dos objetivos da interdisciplinaridade é encontrar o que existe de comum entre as disciplinas, o que poderá ser alcançado apenas com o confronto dialético entre elas, proporcionando a visão do todo e de suas partes.

A implementação de propostas curriculares integradas no âmbito dos cursos que preparam recursos humanos para atuar na saúde ainda são incipientes. Instituições formadoras, que adotaram a interdisciplinaridade em seus currículos, referem o enfrentamento de muitas dificuldades, porém, a medida que o exercício do diálogo e do trabalho em equipe vai ocorrendo, obstáculos vão sendo superados $^{8}$.

A mudança da lógica do ensino deve contemplar metodologias ativas de ensino-aprendizagem, integração entre instituições de ensino e serviços, professores e estudantes, os diversos cursos de uma universidade e as diversas instituições de ensino ${ }^{23}$.

Vale ressaltar que a identificação dos obstáculos denota um olhar crítico, por parte dos docentes, daqueles aspectos que devem ser superados para a consolidação da interdisciplinaridade no curso de Fonoaudiologia.

\section{CONCLUSÃO}

As análises permitiram constatar, por meio do discurso dos professores quanto à concepção de interdisciplinaridade, que eles a definem a partir de um conhecimento indeterminado ou preliminar, demonstrando que o conceito não está consolidado no meio acadêmico analisado. Porém, entende-se que há bases para ampliá-la. No que diz respeito às situações pedagógicas nas quais a interdisciplinaridade seria aplicável, observa-se que ainda são iniciais e pouco frequentes, entretanto, sua presença aponta para domínios potenciais de construção de práticas interdisciplinares, aos quais se chamou objetos fronteiriços.

Atualmente, profissionais de saúde sentem dificuldades no trabalho em equipe, para a troca de experiências, construção de objetivos em conjunto e convivência com diferentes estilos de pensar. Esse fato reforça a ideia de que não há capacitação para tal, durante a graduação para se atuar com equipe multiprofissional, de forma interdisciplinar, de acordo com o que é preconizado pelo sistema de saúde vigente no país. Para construir uma mudança no ensino e na pesquisa, exige-se uma reorganização dos sistemas pedagógicos, reorientando o ensino das ciências a partir de uma visão integradora e proporcionando ao educando uma visão global da realidade ${ }^{24}$. 
Os obstáculos identificados para a efetivação de práticas interdisciplinares apontam a necessidade de maior investimento no estudo sobre o tema, para que ele se coloque também como tema transversal da formação, o que poderá levar à superação das dificuldades apontadas e à consolidação da concepção de interdisciplinaridade na área.

Sugerem-se novas pesquisas que especifiquem a questão da interdisciplinaridade nas práticas curriculares, nos planos de ensino e no próprio projeto pedagógico dos cursos. Espera-se que trabalhos como este possam contribuir com os princípios da interdisciplinaridade no campo da Fonoaudiologia, a fim de expandir os horizontes desse profissional o qual, antes de tudo, precisa entender-se como profissional de Saúde, o qual vive cotidianamente uma realidade que exige dele um olhar plural.

\begin{abstract}
Purpose: to analyze the concept of interdisciplinarity among teachers of the speech therapy course at the University of Vale do Itajaí. Methods: the research was guided by a qualitative approach, through a discourse analysis following the French model, using an in-depth interview as the data collection tool. Results: following the analysis, different subject positions were identified, in which knowledge of interdisciplinarity, the possible pedagogical situations in which it occurs, and the obstacles to interdisciplinary practices, were identified. Conclusion: It was realized that there is still a lack of firmly-grounded knowledge on the subject of interdisciplinarity that can lead to a work model with sufficiently defined and consistent theoretical and methodological principles. Finally, this work reveals a need for greater investment on research that can support the principles of interdisciplinarity in the area of Speech Therapy, in order to expand the horizons of this professional who needs, above all, to understand him or herself as a health professional whose daily practice requires a plural perspective.
\end{abstract}

KEYWORDS: Patient Care Team; Education, Professional; Interdisciplinary Communication

\section{REFERÊNCIAS}

1. Trenche MCB, Barzagui L, Pupo AC. Mudança curricular: construção de um novo projeto pedagógico de formação na área da Fonoaudiologia. Interface Comun Saúde Educ. 2008; 12(27):697-711.

2. Batista SHS. A interdisciplinaridade no ensino médico. Rev Bras Educ Med. 2006; 30(1):39-46.

3. Madeira KH. Práticas do trabalho interdisciplinar na saúde da família: um estudo de caso. [dissertação]. Itajaí (SC): Universidade do Vale do Itajaí; 2009.

4. Fleck L. La gênesis y el desarrollo de un hecho científico. Madri: Alianza Editorial; 1986.

5. Lobo LCG. Ensino das matérias básicas. Rev Bras Educ Med. 1981; 5(2):95-105.

6. Gomes R, Deslandes SF. Interdisciplinaridade na saúde pública: um campo em construção. Rev Latino-Am Enferm. 1994; 2(2):103-14.

7. Pires MFC. Multidisciplinaridade, interdisciplinaridade e transdisciplinaridade no ensino. Interface Comun Saúde Educ. 1998; 2(2):173-202.

8. Vilela EM, Mendes IJM. Interdisciplinaridade e saúde: estudo bibliográfico. Rev Latino-Am Enferm. 2003; 11(4) 525-31.

9. Perini $\mathrm{E}$, Paixão $\mathrm{HH}$, Módena $\mathrm{CM}$, Rodrigues RN. O indivíduo e o coletivo: alguns desafios da epidemiologia e da medicina social. Interface Comun Saúde Educ. 2001; 5(8):101-18.

10. Carvalho V. Acerca da interdisciplinaridade: aspectos epistemológicos e implicações para a enfermagem. Rev Esc Enferm USP. 2007; 41(3):500-7.

11. Alves-Mazzotti AJ, Gewandsznajder F. O método nas ciências naturais e sociais: pesquisa quantitativa e qualitativa. São Paulo: Pioneira; 1998. $150 \mathrm{p}$.

12. Nogueira-Martins MCF, Bógus CM. Considerações sobre a metodologia qualitativa como recurso para o estudo das ações de humanização em saúde. Rev Saude Soc. 2004; 13(3):44-57.

13. Boni V, Quaresma SJ. Aprendendo a entrevistar: como fazer entrevistas em Ciências Sociais. Rev Eletrôn Pós-Graduandos Sociol Polít UFSC. 2005; 2(1):68-80.

14. Pêcheux M. Semântica e discurso: uma crítica à afirmação do óbvio. 2. ed. Campinas: UNICAMP; 1995. 317p.

15. Orlandi EP. Análise do discurso: princípios e procedimentos. Campinas: Pontes; 1998. 100p.

16. Amorim DS, Gattás MLB. Modelo de prática interdisciplinar em área na saúde. Rev Medicina. 2007; 40(1):82-4. 
17. Silva JM. Inter, multi ou transdisciplinaridade, uma questão de comunicação. In: Audy JLN, Morosini $\mathrm{MC}$, organizadores. Inovação e interdisciplinaridade na universidade. Porto Alegre: Edipucrs; 2007. p. 32-57.

18. Carrijo D, Lisboa EP, Bertani IF. Ensaio sobre o tema da prática do serviço social na área da saúde: a interdisciplinaridade. Serviço Social em Saúde. 2003; 2(2):39-54.

19. Silva IZQJ, Trad LAB. O trabalho em equipe no PSF: investigando a articulação técnica e a interação entre os profissionais. Interface Comun Saúde Educ. 2005; 9(16):25-38.

20. Orlandi EP. As formas do silêncio: no movimento dos sentidos. 3. ed. Campinas: Unicamp; 1995.

21. Cutolo LRA. O SUS e a formação de recursos humanos. Arq Catarin Med. 2003; 32(2):49-59.
22. Teixeira SF. Saúde da família, promoção e vigilância: construindo a integralidade da atenção à saúde no SUS. Rev Bras Saúde Fam. 2004; 7: 10-23.

23. Lima A, Pereira LA. Articulação e parceria na construção de mudanças na graduação. Boletim informativo da rede unida. 2005; 20(44):18. Disponível em: URL: http://www.fnepas.org.br/pdf/ publicacao/boletim_rede_unida.pdf. Acesso em 12 mar 2009.

24. Félix SBCM, Cutulo LRA. Objetos fronteiriços possibilitando o desenvolvimento da interdisciplinaridade durante a graduação em fisioterapia. [dissertação] Itajaí (SC): Universidade do Vale do Itajaí; 2005. $122 f$.

RECEBIDO EM: 03/07/2007

ACEITO EM: 05/03/2009

Endereço para correspondência:

Renata Mancopes

Rua Jacinto Gomes, 410 ap. 3

Porto Alegre - RS

CEP: 90040-270

E-mail: renatamr@ufcspa.edu.br 